\title{
Plant-based Natural Product
}

National Cancer Institute

\section{Source}

National Cancer Institute. Plant-based Natural Product. NCI Thesaurus. Code C106104.

Any mixture of substances or products derived from a plant or from part of a plant. 